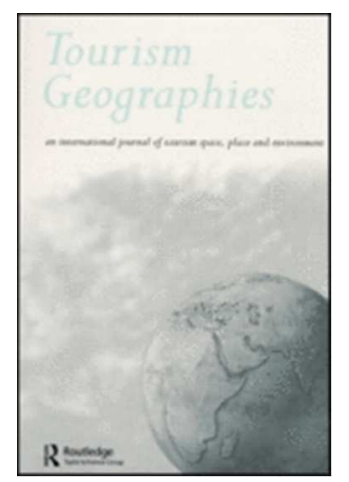

\title{
Linking Tourism, Retirement Migration and Social Capital
}

\begin{tabular}{|r|l|}
\hline Journal: & Tourism Geographies \\
\hline Manuscript ID: & Draft \\
\hline Manuscript Type: & Research Article \\
\hline Keywords: & $\begin{array}{l}\text { United Kingdom < EUROPE, Spain < EUROPE, retirement migration, } \\
\text { tourism, social capital, leisure }\end{array}$ \\
\hline
\end{tabular}

\section{SCHOLARONE ${ }^{\mathrm{T}}$}

Manuscripts 


\title{
LINKING TOURISM, RETIREMENT MIGRATION AND SOCIAL CAPITAL
}

\begin{abstract}
A general trend in the study of international retirement migration has been the increased attention paid to the social contacts and network connections of the migrants in both the destination and origin areas. These studies have examined the extent to which migrants build social relationships with their neighbours and the host society while also maintaining social links with their countries of origin, addressing the central role that leisure travel plays in sustaining increasingly dispersed social networks and maintaining the social capital of these networks and of the individuals involved in them. This paper explores the relevance of transnational social networks in the context of international retirement migration providing an in-depth analysis of the nature, meaning and extent of these transnational social networks. Building on the concept of social capital and Putnam's (2000) distinction of bonding and bridging social, we propose a framework for the analysis of the migrants' international social networks. The results of a study conducted among 365 British retirees living in the coast of Alicante (Spain) show both the strength of the retirees' international bonding social capital and the role of 'visiting friends and relatives' travel and communication technologies in sustaining the migrants' transnational social practices and, ultimately, their international social capital. It also evidences the reinforcing links between tourism-related mobility and amenity-seeking migration in later life.
\end{abstract}

KEY WORDS: International retirement migration, tourism, social capital, Spain 


\section{Introduction}

An emerging thread of research on tourism geographies relates to lifestyle migration and the quest for a better life elsewhere (for a review see Benson and O'Reilly 2009b). The concept of lifestyle migration encapsulates the implications and varied manifestations of leisure mobility in contemporary societies. Among lifestyle migration, international retirement migration (hereafter IRM) has been one of the most widely researched forms of leisure/lifestyle mobility. In Europe, the study of IRM has traditionally focused on the analysis of flows from northern to southern regions, the nexus between tourism-related mobility and migration in later life and the impacts of such population flows at the destination level (for a review see Casado-Díaz 2011). Despite the increasing number of studies centred in the analysis of the experiences of IRM migrants in their new destinations (O'Reilly 2000; King et al. 2000; Huber and O'Reilly 2004; Oliver 2007; Gustafson 2008 and 2009; Casado-Diaz 2009), the nature and intensity of the social ties maintained by the migrants in their home countries, both for practical and emotional reasons, remains underresearched.

Therefore, the aim of this article is to contribute to our understanding of the nature and meaning of contemporary mobility in the context of IRM. Using the concept of social capital as a theoretical framework, this paper examines the migrants' interpersonal relationships and transnational network connections with their country of origin. For the purpose of this study, and following Portes (1998), social capital is defined as a social resource that is derived from the formal and informal relationships that exist between the members of a community. It is argued that retired migrants possess, to different degrees, both local and international social capital: they bring with them their 'existing' social capital and then create 'new' social capital in their new place of residence (Casado-Díaz 2009).

In this paper we focus on the analysis of the international component of social capital. Specifically, we consider two aspects of the migrants' social lives as indicators of their international social capital: the intensity of bidirectional VFR tourism flows (i.e., participating in and hosting friends and relatives visits), and the social contacts with friends and/or family living in the UK. Then, we analyse how migrants' international social capital may differ when taking into account different 'explanatory' variables that include sociodemographic characteristics (age and gender), and what we might consider 'bridging' related variables (knowledge of the local language and length of residence in the local area), and 'bonding' related variables (ownership of property in the home country). 
The paper is divided in four sections. The first discusses recent developments within the field of lifestyle migration, and particularly of IRM. The second addresses the usefulness of the concept of social capital as a theoretical framework for the analysis of the migrants' social ties and networks 'back home'. The third and fourth sections reports the data, methodology and results derived from our study of British retirement migration to Spain based on questionnaire responses from 365 British retirees living in the Costa Blanca, Spain. The final section presents the main conclusions and discusses the implications and the relevance of the strong social ties that these lifestyle older migrants have maintained with their country of origin.

\section{Tourism and lifestyle migration: searching for the good life}

Tourism has significantly influenced the mapping of potential destinations for different forms of leisure-oriented mobility, such as second home ownership, amenity-seeking seasonal migration or international retirement migration, and has also contributed to the intensification and diversification of contemporary mobility in recent decades (King et al. 2000; Williams and Hall 2000, Williams et al. 2000; Rodriguez 2001; Gustafson 2002). Research in this field has recently focused on the concept of lifestyle migration, which considers the implications and varied manifestations of leisure-oriented mobility in contemporary societies. As noted by Benson and O'Reilly (2009a: 621) lifestyle migration can be conceptualised as the migration of 'relatively affluent individuals, moving either part-time or full-time, permanently or temporarily, to places which, for various reasons, signify for the migrants something loosely defined as quality of life'. While geographers have focused predominantly on the analysis of the spatial distribution and scale of these flows of migrants, the characteristics of the destinations, the links between tourism and seasonal or permanent migration and the physical impacts at the local level, sociologists and anthropologists have turned their attention to the trajectories, everyday lives, lifestyle choices, and experiences of these older migrants and explored the implications for host and home communities. The importance of issues of gender, age, place, identity, class, nation and community among these amenity-seeking migrants has also been central to researchers in this field (see Benson and O'Reilly 2009b).

Within lifestyle migration, international retirement migration (IRM) has been one of the most widely researched forms of lifestyle mobility. In Europe, amenity seeking migration in later life has typically originated in northern and central countries (mainly the United Kingdom, Germany, Scandinavian countries and the Netherlands) favouring southern Mediterranean regions and Atlantic island and coastal regions with climatic and lower cost- 
of-living advantages. These groups of older people have above-average opportunities for international travel. They have the financial resources, are no longer restricted by employment obligations, and the majority have neither dependent children nor parents in need of daily personal care. These amenity-led migrants are primarily motivated by the desire to engage in a more satisfying way of life and in order to do so they search for new spaces that will provide them with more opportunities to enjoy their post-retirement lives. Many studies reported previous tourist visits as the main connection to the area prior to the move (Casado-Díaz et al. 2004) and the purchase of second homes as a stepping stone towards international retirement migration (Muller 2002; Hall and Muller 2004). Indeed, the development of mass tourism in southern Europe widened the opportunities for international leisure travel and provided the necessary services and amenities that made these regions attractive for international tourists, second-home owners and future migrants (Gustafson 2002; Rodriguez 2001; Williams et al. 2000). Likewise, the different forms of consumptionled mobility generated significant reciprocal flows of visiting friends and relatives highlighting the important nexus between tourism and migration (Williams and Hall 2000; Illés and Michalkó 2008; Gustafson 2008). A series of historical developments and material conditions have enabled growing numbers of lifestyle migrants to participate in these forms of contemporary mobility. They include increased life expectancy, higher incomes and greater affluence, the initial relatively lower cost of living and cost of properties in southern Mediterranean countries and the familiarity of travelling, working and owning a second home abroad (King et al. 2000). Likewise, the rapid development of communication and transportation technologies has made possible for greater numbers of migrants to engage in 'transnational lifestyles' while sustaining links with their home countries (King et al. 1998; Gustafson 2001; Bozic 2006; Casado-Díaz 2009). As argued by Warnes (2009: 359), 'the ease and low cost of international travel is allowing many older people to exploit, maintain and continue to develop residential opportunities, social networks and welfare entitlements in more than one country'.

\section{A research framework for the study of international retirement migration}

Pahl (2000) suggests that the term social capital can be seen as an umbrella for explaining the nature of personal communities, social networks and other forms and styles of social connectedness in contemporary societies. The role of migrant networks in the formation of social capital has been much discussed in recent migration studies (Castells and Miller 2003; Ryan et al. 2008; Anthias 2007). Social networks might provide different types and level of 
social support and, for migrants, these forms of support very often cross national boundaries allowing for their transnational links to still play a supportive role even after migration (Ryan et al. 2008; Iorio and Corsale 2012). However, as argued by Anthias (2007), not all social networks and social bonds can be referred to as social capital. It is the ability to 'mobilise' these resources for the pursuit of advantage, or the mitigation of disadvantage, that gives them value as 'capital' and make the concept of social capital meaningful (Anthias 2007: 788). It is both, the personal relationships that individuals accumulate when they interact with each other over time, formally and informally, and the amount and quality of the resources derived from those social relationships, what constitute the essence of social capital (Bourdieu 1986).

Recent research on IRM has explored how retired migrants build social networks in their new communities of residence and the strategies adopted to also retain close ties with their relatives and long-standing friends in their home countries (Huber and O'Reilly 2004; Casado-Díaz 2009; Gustafson 2008 and 2009). However, one question that arises in relation to the communities that retired migrants form is the types of social capital generated. As noted by Putnam (2000), different types of networks give rise to different forms of social capital. Particularly relevant to this study is his distinction between bonding social capital and bridging social capital. He argues that bonding types of social capital refer to close social connections between people and is characterised by strong bonds among family members, close friends, neighbours or among members of the same ethnic group. Bonding social capital might also arise within a particular social group bound together by shared identities, interests and place of residence (Healy 2003). This type of social capital, based on close family and friendship ties, is said to be beneficial to the self-interest of the individual or small groups, and generally good for "getting by" in life (Putnam 2000: 22). Bridging capital, on the other hand, tends to be inclusive, encompassing people across different social groups and backgrounds, thus encouraging the formation of broader identities and collectivities and, ultimately, social cohesion (Parker and Song 2006: 180). This type of social capital is based on common interest rather than personal closeness or common identification. If bonding capital was good for "getting by", bridging types of social capital are supposed to be crucial for helping individuals to "get ahead" in life (Putnam 2000: 19).

It is argued that retired migrants possess, to different degrees, both local and international social capital: they bring with them their 'existing' social capital and then create 'new' social capital in their new place of residence (Casado-Díaz 2009). In this paper we focus on the analysis of the international component of social capital. In this respect, a compelling aspect 
within the framework of IRM is to examine the migrants' interpersonal relationships and transnational network connections that is, their international social capital, and the effect that different types of social capital may exert on it. So, after relocating to the new home, have migrants' ties with their homeland weakened or have the migrants succeeded in keeping up such relationships? Which factors have influenced this behaviour? In order to investigate these questions, the study analyses migrants' mobility patterns (reciprocal visits by friends and relatives) and their contacts (by phone, internet, etc) to ascertain the strength of the migrants' bonds with their home country and, ultimately, the strength of their international social capital.

\section{International social capital: transnational mobility patterns and social contacts}

Retired migrants might establish ways of keeping the links with their long-time friends and relatives back in their countries, such as participating (and reciprocating) in VFR tourism and through long-distance (virtual) communication (regularity of social contact with others, such as speaking, writing, emailing, etc.). This interplay between physical travel and other ways of communicating and maintaining social ties 'at a distance' (Urry 2007, cited in Gustafson 2009:83) enable the migrants to sustain the international social ties and networks, and the resources derived from these. Communication technology has greatly enabled the development of dense social, cultural and economic networks among transnational communities in which mobility has become the norm (Duval 2004). But while telecommunication may facilitate on-going emotional support among migrant communities (Ryan et al. 2009) individuals also rely on physical mobility for the maintenance of geographically expanded and increasingly disperse social networks (Larsen et al. 2006). Leisure scholars have noted the role of leisure in the development of social capital and the strengthening of social ties (Glover et al. 2005; Glover and Hemingway 2005; Rojek 2005). Research has shown how leisure might provide individuals with a sense of belonging, support and social interactions, hence assisting them in forming community networks and bonds that are important for social cohesion (Bush and Baum 2001). Similarly, it has been argued that leisure travel, such as visiting friends and relatives (VFR) tourism, plays an important role in sustaining geographically disperse social networks (Lew and Wong 2002) and maintaining the social capital of these networks and of the individuals involved in them (Larsen et al. 2006; Larsen 2008). Leisure (travel) can thus act as a social lubricant for social capital generation (Glover et al. 2005). In the context of IRM leisure has certainly facilitated both informal and formal relationships among the members of communities of older northern 
Europeans and the nature of many of these clubs and associations reveals a strong leisure component (O’Reilly, 2000; Casado-Díaz 2006; Gustafson 2008). It has been argued that these newly formed networks of relationships provide the retirees with an informal communal system of self-help and reciprocity and give them a strong sense of community (Casado-Díaz 2009).

Previous work has also discussed the strength of bonding types of social capital among British retirees living in the Costa Blanca, Spain, and the lack of bridging social capital, specifically in terms of social ties with members of the Spanish local community (CasadoDiaz 2009). This study found very limited bridging forms of social capital among this community of retired British migrants, a community bonded by their shared nationality, language, class and interests. Although there were some links with other nationalities and with the host community, the social networks the respondents belonged to were predominantly British. The findings suggested that the lack of contact with the surrounding society was mostly associated to the retirees' lack of knowledge of the Spanish language. The migrants' inability to communicate in Spanish was clearly detrimental for fostering bridging types of social capital at the local level while at the same time reinforced their need for 'bonding' with other members of the British community. As noted by Ryan et al. 'migrants' ability to mobilise social capital and successfully engaged in bridging may depend upon the cultural capital (language, skills and educational qualifications) at their disposal' (2008: 677). The general lack of contact with the Spanish local community (a source for acquiring social capital of the 'bridging' type) was not an isolated feature of British retirement migration to Spain. Similar results were found for the Swiss and Swedish retirees who had relocated on a seasonal or permanent basis to this country (see Huber and O'Reilly 2004 and Gustafson 2009). Similarly, it is reasonable to assume that migrants' lack of knowledge of the local language might reinforce bonds with the country of origin. Therefore, we propose that the migrants' international social capital may differ depending on their ability in the local language.

Although the process of migration may weaken family and kinship networks depleting migrants from a crucial form of social capital (Coleman 1990; Portes 1998) it might also encourage migrants to develop strategies to keep their existing international social capital (in their home countries) somehow "alive". One way to maintain bonding networks with their homelands and reaffirm social belonging may rely on having another home in their country of origin (Iorio and Corsale 2012: 25). However, this must be seen with caution because as noted by Williams et al. (2000:37), although the retention of a home in the UK is an 
important facilitator of a peripatetic life style is not necessarily a sign of attachment to it. There may be many circumstances for this, such as market conditions for selling or individual financial strategies (i.e., it may be viewed as an investment), or the fact that they did not own homes at the time they retired. Therefore, we propose that another factor that might influence the ability of the migrants to mobilise the resources attached to their international social ties might be the ownership (or lack) of property in the UK.

Research on IRM has also highlighted the role that age and gender might play in explaining differences in migrants' social practices (Casado-Díaz et al. 2004; Casado-Díaz 2006). Along with age, we examine the effect of 'length of time resident in the local area' in the migrants' transnational practices in order to further explore the 'time' effect on the variables analyzed.

\section{Methodology}

In order to explore the proposed framework, a survey was conducted among British retirees living in the Costa Blanca, Spain. The questionnaire was administered to British retirees aged 50 or more years who lived in Spain for at least four months a year. As no sampling frame of immigrants exists, and due to the high levels of participation in associations reported among retirees in previous studies (Casado-Díaz et al. 2004), access to respondents was sought through the University of the Third Age (U3A), a non profit organisation run by older British volunteers and with local branches in the UK and abroad. Although each U3A organises their own social and cultural activities independently, many of the branches located in the Costa Blanca hosted similar leisure-oriented groups based around sports, arts and hobbies or more "casual" leisure (such as dining at home). The ethos of the U3A is to draw upon the knowledge and skills of their own members for the setting up of interest groups. At the time of the research, there were more than 3,000 U3A members on the Costa Blanca area, making them the largest British social group in the region. The survey used self-completion questionnaires distributed through the branches of the U3A on the Costa Blanca. Three hundred and sixty nine questionnaires were collected via attendance of social meetings held at the several branches of the U3A in the Costa Blanca, where the self-administered questionnaires were distributed and collected. Four questionnaires were unusable due to incomplete responses, leaving a total sample size of 365 .

In order to investigate the migrants' social capital, this research framework considers two aspects of their social lives: the intensity of bidirectional VFR tourism flows (i.e., participating in and hosting friends and relatives visits), and the social contacts with friends 
and/or family living in the UK. Mobility patterns were examined by using two main indicators: return visits to the UK and visits from friends and relatives. 'Return visits to the UK' was measured with four items: two metric scales, 'number of visits to the UK last year' and 'number of weeks spent in UK last year', and two non-metric (nominal) scales, 'reasons for visit UK' (visit friends, visit relatives, leisure, work/business, to access medical services, other) and 'accommodation used in UK' (own, rented, paid, friends or relatives, other). 'Visits from friends and relatives' was measured with three non-metric items: 'visitors from UK' (Are you ever visited in Spain by relatives/friends from your country of origin?), 'people from UK visiting last year' (children and/or grandchildren, other adult relatives, friends or acquaintances), and 'number of weeks spend by people from UK during their visit'. The questionnaire also included a variable measuring the reasons for not having received visits in the previous year. Transnational social contacts were examined by means of two non-metric scales: 'contacts with UK through phone, fax and/or mobile' and 'contacts with UK through Internet' (daily, every week, several times a month, once a month, at least once a year, never). Finally, we consider age and gender, the 'length of time resident in Spain' (number of years) and 'knowledge of the local language' (none, some knowledge, quite fluent, fluent).

Table 1 summarises the social and educational characteristics of the sample of British retirees interviewed for this study. The average age of the respondents was 65 years with a slight predominance of women among the sample. This might be explained by the fact that many of the social activities organized by members of the U3A in the Costa Blanca were usually led and supported by women and since the questionnaires were distributed and collected in these social gatherings there was a slight over representation of females in the sample. Most of the respondents were married or lived with their partner (80\%) and half of them had completed a university or college qualification. Prior to their move to Spain, $60 \%$ of the respondents had no experience of living abroad, and in terms of their previous employment, there was a predominance of professional (41.6\%) and managerial and technical (24.9\%) occupations. At the time of completion, $97 \%$ of those interviewed stated their current occupation as "retired". The majority considered themselves full-time residents $(77.8 \%)$ and owned their homes in Spain (83.6\%). In general, the socio-demographic characteristics of the respondents were in line of previous studies examining foreign retirement migration in Europe (e.g., Casado-Díaz et al. 2004).

Take in Table 1 


\section{Results}

This section presents two sets of data related to the migrants' transnational network connections: VFR tourism (return visits to the UK and visits by friends and family), and strategies for maintaining the social ties with their country of origin. The analysis of the survey results combines descriptive statistics and analyses of variance (ANOVA) in order to identify significant differences amongst the main variables. Note that in ANOVA analyses, VFR tourism is limited to the 'Return visits to the UK' variable, measured by the item 'number of weeks spent in UK last year'. This item is believed to better measure the degree of contact with the country of origin given that it reflects the total amount of time spent in UK independent of the number of visits taken. ANOVA analyses were not conducted for the remaining items due to their qualitative nature. Regarding social contacts we employ both measures: 'contacts with UK through phone, fax and/or mobile' and 'contacts with UK through Internet'. For the purpose of the analysis, age is coded into three categories: the youngest group (YG) includes those respondents aged 59 years or less, the medium group (MG) includes those respondents aged between 60 and 69 years, and the oldest group (OG) includes those respondents age 70 years or more. Length of time resident in Spain is coded into four categories: 0-3 years (LR1), 3-6 years (LR2), 6-9 years (LR3), and 10 or more years (LR4). Knowledge of the local language is coded into four categories: a few words/none (KNW1), some knowledge (KNW2), quite fluent (KNW3) and fluent (KNW4). Finally, type of accommodation used when visiting UK is considered a proxy of ownership of property back in the country of origin (a bonding type of social capital) for further analyses and is coded into three categories: own accommodation (ACC1), with friends/relatives (ACC2) and paid accommodation (ACC3). The level of satisfaction showed by those interviewed with regard to these social contacts/social ties with the friends and family back in the UK is also discussed.

\section{Transnational mobility patterns: VFR tourism to and from country of origin}

In order to analyse the strength of the migrants' international social networks, the proposed research framework considers in the first place, the intensity of VFR tourism, both to and from their country of origin.

Table 2 summarizes the retirees' mobility patterns regarding return visits to UK. The frequency of return visits to the UK is a powerful indicator of the strength of the social ties kept by the retirees with their communities of origin. The questionnaire results showed that most of the retirees visited the UK regularly in the previous year in order to see their family 
and friends. Approximately a third of the retirees had travelled to the UK at least once in the previous year but an ever higher proportion had taken two or more trips (62\%) suggesting very strong links with friends and relatives in their country of origin. When asked about the reasons for those visits, the respondents stated that they were primarily for the purpose of visiting family (78\%) and friends (44\%), a fact that was also reflected in their preferred choice of accommodation (54\% stayed with friends or family) and the length of the visit, between 1 and 6 weeks in $61.6 \%$ of the cases. Only a minority (10\%) of those interviewed stated that they had not traveled to the UK in the past year.

\section{Take in Table 2}

Additionally, Table 3 shows that, as well as being participants in these tourism flows, most respondents became recipients of VFR travel. The majority $(98.1 \%)$ hosted visitors from the UK during the past year with most visits lasting between one and two weeks. The most frequent visitors were children and/or grandchildren (76.4\%), although the number of other adult relatives that travel to Spain to see them was also important (50\%). The strong kinship networks maintained in the UK were also evident by the high proportion of respondents that had also hosted visits by friends (66.8\%). The scarce number of respondents $(1.6 \%)$ that did not receive visits from the UK during the previous year believed that the mains reasons for this could be the increasing cost of international travel and the fact that they might not have sufficient room to lodge them, not because they might have lost contact with them.

\section{Take in Table 3}

These results exemplify the significance of VFR tourism to international retirement destinations and suggest that the respondents have managed to retain close ties with their relatives and long-standing friends in their home countries through both participating and hosting visits from friends and relatives, as stated in previous studies on IRM (Williams et al., 2000; Huber and O'Reilly 2004; Gustafson 2008; Casado-Díaz 2009). The amount of visits (frequency of contacts) evidences the fact that these retirees still rely heavily on existing social networks in their home countries. These results are relatively surprising and reflect that these set of migrants are not drifting away the longer they spend in Spain. One possible explanation might be on the personal circumstances of these set of migrants, where many of them are well educated and resourceful, and they are aware of the importance of maintaining 
their 'international bonding social capital' for emotional as well as instrumental reasons (e.g., possible return, onset of illness).

To shed some light on these results, we ran Anova tests in order to explore the existence of significant differences amongst the main variables. Regarding sociodemographic characteristics, our findings show that there are no gender differences for the variable 'number of weeks spent in UK' $(t=0.06, p>0.05)$. However, there are some significant differences regarding age. The ANOVA test evidences that the older the respondents the least number of visits they took to the UK $(F=4,418, p<0.05)$, with the oldest group showing a significant different (lower) mean (that is, less weeks spent in UK) in comparison to the medium group (Mean difference: $\mathrm{MG}-\mathrm{OG}=0.463, p<0.05$ ). Results also indicate that there are no differences regarding 'length of time resident in the local area' in terms of the 'number of weeks spent in UK' $(F=0.687, p>0.05)$ but there are regarding 'knowledge of the local language' $(F=4.14, p<0.01)$. Specifically, we observe that the less knowledge of the local language declared the more weeks spent in UK. The two groups that state they have a poor knowledge of Spanish spend more weeks in UK than the other two groups (Mean differences: KNW1-KNW4=1.25, $p<0.01$; KNW1-KNW3=0.81, $p<0.01$; KNW2-KNW4=1.02, $p<0.01$; $\mathrm{KNW} 2-\mathrm{KNW} 3=0.58, p<0.01$ ). Also, as expected, 'ownership of property in the UK' has an effect in the number of weeks spent in UK. Those who still own properties in the UK spend more weeks on average than those who do not (Mean differences: ACC1-ACC2=1.16, $p<0.01 ; \mathrm{ACC} 1-\mathrm{ACC} 3=1.38, p<0.01)$.

Transnational social contacts: keeping in touch 'at a distance'

As well as visiting (and being visited by) long-term friends and family in their country of origin, most respondents kept in touch with them by regularly phoning and/or emailing them. Table 4 shows the intensity of the respondents' contacts with friends and family back in the UK. A large proportion of the respondents (73\%) have contact with the UK on a daily/weekly basis through phone, fax and/or mobile, and around $55 \%$ of the sample used the internet to communicate with friends and/or family back in the UK also on a daily or weekly basis. The majority of the respondents also 'felt' they had kept close relations with their friends and relatives in the UK (see Table 5). Most of them 'strongly agreed' or 'agreed somewhat' to the following statements 'I regularly keep in touch with friends/relatives in the UK' (93\%); 'Back in the UK I have close friends who I could always turn to for help' (80\%); 'I keep close personal relations with friends back in the UK' (70\%). These results evidence the intensity of the contacts and also the importance of communication technologies, particularly 
the internet, for the maintenance of their kinship and friendship networks and the resources derived from them, which is their transnational social capital.

\section{Take in Table 4}

Take in Table 5

The survey also included a number of questions designed to ascertain the level of satisfaction of the respondents with a series of statements related to the frequency and intensity of those contacts with friends and family back in the UK (Table 6). Most of the respondents were either 'very satisfied' or 'somewhat satisfied' with the contacts maintained with family and friends in the UK (82\%), the frequency of visits by friends and family (72\%) and the frequency of their visits to the UK (65\%). Again, these results confirm the presence of high levels of international social capital for the sample analyzed (in terms of VFR tourism and social contacts).

\section{Take in Table 6}

Anova tests were used to explore the existence of significant differences for the explanatory variables. No significant differences are found between men and women in terms of 'frequency of contacts with UK through Internet' $(t=-0.41, p>0.05)$ and 'frequency of contacts with UK through phone/fax/mobiles' $(t=-0.39, p>0.05)$. Regarding age, no significant differences are found for the variable 'frequency of contacts with UK through phone/fax/mobiles' $(F=0.51, p>0.05)$ but they arise for the variable 'frequency of contacts with UK through Internet' $(F=11.10, p<0.01)$. Specifically, we find that the older the respondents the least frequency of Internet-based contacts with people back in the UK (Mean differences: $\mathrm{YG}-\mathrm{OG}=1.26, p<0.01$; $\mathrm{MG}-\mathrm{OG}=0.71, p<0.01$; $\mathrm{YG}-\mathrm{MG}=0.55, p<0.05)$. Results also show differences regarding 'length of time resident in the local area' in terms of the 'frequency of contacts with UK through phone/fax/mobiles' $(F=2.81, p<0.01)$ and also for 'frequency of contacts with UK through Internet' $(F=9.15, p<0.01)$. Those migrants that have lived in Spain for longer have fewer contacts than the 'youngest' group (those living less than 3 years in Spain). This has been observed for 'frequency of contacts with UK through phone/fax/mobiles (Mean differences: LR1-LR4=0.41, $p<0.05$ ) and for 'frequency of contacts with UK through Internet' (Mean differences: LR1-LR4=1.29, $p<0.01$; LR2LR4=1.09, $p<0.01$ ). No significant differences are found for the factor 'knowledge of the 
local language', nor for 'frequency of contacts with UK through phone/fax/mobiles' $(F=0.71$, $p>0.05)$ or 'frequency of contacts with UK through Internet' $(F=0.77, p>0.05)$. Lastly, 'ownership of property in the UK' has no effect in the frequency of contacts with UK for both 'frequency of contacts with UK through phone/fax/mobiles' $(F=1.76, p>0.05)$ and 'frequency of contacts with UK through Internet' $(F=2.40, p>0.05)$.

\section{Conclusions}

This paper has contributed to recent developments in the study of IRM by exploring the relevance of transnational social networks and the role that leisure travel, particularly VFR tourism, plays in maintaining these social ties and, ultimately, in sustaining the migrants' transnational social capital. We have argued the potential of the concept of social capital and Putnam's (2000) typology of bridging and bonding forms of social capital for the analysis of the local and transnational social practices of international retired migrants. Results show that, as well as creating (local) bonding social capital in Spain, British retirees have succeeded in maintaining their international bonding social capital by regularly keeping in touch and visiting (and being visited by) their families and friends back in their home country. More specifically, the analysis of the data reveals both the strength of the retirees' international bonding social capital and the role of VFR travel and communication technologies in sustaining these transnational social practices and, ultimately, these 'transnational lifestyles' among amenity-seeking older migrants. These findings are in line with previous research on the importance of VFR tourism to international retirement destinations (Williams et al. 2000; Huber and O’Reilly 2004; Gustafson 2008; Casado-Díaz 2009). The analysis suggests that the older the respondents the fewer number of visits they took to the UK and that those with less knowledge of Spanish spent more weeks in their home country (that was also the case for those who still maintained a property in the UK). These results might indicate that knowledge of the local language acts as a 'bridge' for contact with the local community hence reducing the frequency of the visits to the home country. Similarly, the migrants' social ties with the UK do not necessarily weaken over time, as might be expected with international migrants, and this is reflected in the results regarding age, except when the migrants have reached a high level of 'integration' in the local community as a result of their ability to speak Spanish. To this effect, British retirees seem to be participants of an ongoing migration process by which they are successfully maintaining a varying degree of attachment to both their home countries and their new places of residence. 
As for transnational social contacts, a large proportion of the respondents stated that they were regularly in touch with friends and/or family back in the UK. They also felt that they had successfully maintained 'close personal relations with friends back in the UK' and expressed a high degree of satisfaction with these personal relationships 'at a distance'. These results suggest a deliberate effort of 'keeping up' their international bonding social capital and, as argued by Ryan et al., their 'transnational sources of emotional support' (2008: 673). The analysis of the data suggests that these social contacts are independent of gender or age, except for the use of internet that is lower in the oldest group. Additionally, results show that those migrants that have lived in Spain for longer have fewer social contacts with UK than the 'youngest' group (those living less than 3 years in Spain).

Similarly to the findings reported by Portes (1998:14), it would seem that British retirees have compensated for the absence of bridging forms of social capital at the local level by putting an emphasis on kin and friendship ties as a source of social support, one of the basic functions of social capital. While previous studies have noted the salience of friendship among international retired migrants, particularly for the creation of bonding types of social capital in their new communities of residence (Casado-Díaz 2009), the results from this study acknowledge the relevance of the migrants' social ties 'back home'. As argued by Gustafson (2009) the seasonal mobility of the retirees gives an additional meaning to the concept of lifestyle migration since their recurrent migration becomes part of their lifestyle in an attempt to achieve the best of both words. Migration thus should be seen as an ongoing process rather than a one-time permanent move (Gustafson, 2008) with the regular (and reciprocal) visits enabling migrants to sustain and reinforce their existing international bonding social capital, a capital derived from their existing strong kinship and friendship ties 'back home' and the social resources attached to them.

It is also important to bear in mind that those interviewed through the U3A meetings are prone to report higher levels of sociability than others who might not belong to similar leisure-based associations. Future studies will need to widen sampling frames in order to include not only those migrants that are members of leisure-based associations but also those who might not. Similarly, this study has not focused on other groups of older European migrants with fewer resources and who might not have been so successful in their search for a better lifestyle (O'Reilly 2007). Another area of comparative research that will require further consideration is the extent to which international retired migrants have succeeded in getting "the best of both worlds", that is, whether they have both managed to create new social ties in the destination country (local social capital) and maintained the existing ones in 
their country of origin (international social capital) and how this is reflected in their overall level of satisfaction with their new post-retirement lifestyle abroad. Migrants might access social support through a combination of established and newly formed networks involving a mixture of contacts in both the countries of origin and destination (Ryan et al. 2008: 673) so much research is needed into the ways in which the social networks established by the migrants, both locally and transnationally, and the resources attached to them, will evolve in the future. Similarly, the impacts of IRM in the receiving communities remain significantly under researched. The ways in which the spatial concentration of large (and highly mobile) communities of retired EU migrants might alter economic, social, political and demographic structures at the destination level together with the demands that they might impose on local state services (particularly health and welfare services due to the migrants' old age) are issues that merit further attention. 


\section{References}

Benson, M. \& O'Reilly, K. (2009a) Migration and the search for a better way of life: A critical exploration of lifestyle migration, The Sociological Review, 57(4), pp. 608-625.

Benson, M. \& O'Reilly, K. (2009b) Lifestyle Migration: Expectations, Aspirations and Experiences (Farnham: Ashgate).

Bourdieu, P. (1986) The Forms of Capital, in: J. G. Richardson (Ed.) Handbook for Theory and Research for the Sociology of Education, pp. 241-258 (New York: Greenwood).

Casado-Díaz, M. A, Kaiser, C. \& Warnes, A. M. (2004) Northern European retired residents in nine Southern European areas: characteristics, motivations and adjustment, Ageing and Society, 24(3), pp. 353-81.

Casado-Díaz, M. A. (2006) Retiring to the Costa Blanca: A cross-national analysis, Journal of Ethnic and Migration Studies, 32(8), pp. 1321-1339.

Casado-Díaz, M. A. (2009) Social capital in the sun: bonding and bridging social capital among British retirees, in: M. Benson \& K. O'Reilly (Eds) Lifestyle Migration: Expectations, Aspirations and Experiences, pp. 87-102 (Farnham: Ashgate).

Casado-Díaz, M. A. (2011) Exploring the geographies of lifestyle mobility: current and future fields of enquiry, in: Wilson, J. (Ed) The Routledge Handbook of Tourism Geographies, pp. 120-125 (London: Routledge).

Castles, S. \& Miller, M. (2003) The Age of Migration: International Population Movements in the Modern World (Basingstoke: Palgrave).

Coleman, J. (1990) Foundations of Social Theory (Cambridge Mass: Belknap Press of Harvard University).

Duval, D. T. (2004) Conceptualising return visits: a transnational perspective, in: Coles, T. E. \& Timothy, D. J. (Eds) Tourism, Diasporas and Space: Travels to Promised Lands, pp. 50-61 (London: Routledge).

Glover, T. D. \& Hemingway, J. L. (2005) Locating leisure in the social capital literature, Journal of Leisure Research, 37(4), pp. 387-401.

Glover, T. D., Parry, D. C., \& Shinew, K. J. (2005) Building relationships, accessing resources: mobilising social capital in community garden contexts, Journal of Leisure Research, 37(4), pp. 450-474.

Gustafson, P. (2002) Tourism and seasonal retirement migration, Annals of Tourism Research, 29(4), pp. 899-918.

Gustafson, P. (2008) Transnationalism in retirement migration: The case of North European retirees in Spain, Ethnic and Racial Studies, 31(3), pp. 451-475.

Gustafson, P. (2009) Your home in Spain: Residential strategies in international retirement migration, in: M. Benson \& K. O'Reilly (Eds) Lifestyle Migration: Expectations, Aspirations and Experiences, pp. 69-86 (Farnham: Ashgate).Hall, C. M. \& Müller, D. (2004) Tourism, Mobility and Second Homes: Between Elite Landscape and Common Ground (London: Channelview Publications).

Huber, A. \& O'Reilly, K. (2004) The construction of Heimat under conditions of individualized modernity: Swiss and British elderly migrants in Spain, Ageing and Society, 24(3), pp. 327-51.

Illés, S. \& Michalkó, G. (2008) Relationships between international tourism and migration in Hungary: Tourism flows and foreign property ownership, Tourism Geographies, 10(1), pp. 98-118.

Iorio, M. \& Corsale, A. (2012) Diaspora and tourism: Transylvanian Saxons visiting the homeland, Tourism Geographies, DOI: 10.1080/14616688.2012.647327.

King, R., Warnes, A. M. \& Williams, A. (2000) Sunset Lives: British Retirement Migration to the Mediterranean (Oxford: Bergamon). 
Larsen, J. (2008) De-exoticising tourist travel: Everyday life and sociality on the move, Leisure Studies, 27(1), pp. 21-34.

Larsen, J., Urry, J. \& Axhausen, K. (2006) Mobilities, Networks and Geographies (Ashgate: Aldershot).

Lew, A. \& Wong, A. (2002) Tourism and the Chinese Diaspora, in: C.M. Hall \& A.M. Williams (Eds) Tourism and Migration: New Relationships Between Production and Consumption, pp. 205-219 (Dordrecht: Kluwer Academic).

Oliver, C. (2007) Retirement migration: Paradoxes of Ageing (London: Routledge).

O'Reilly, K. (2000) The British on the Costa del Sol: Transnational Identities and Local Communities (London: Routledge).

O'Reilly, K. (2007) Intra-European migration and the mobility-enclosure dialectic, Sociology, 41, pp. 277-293.

Pahl, R. (2000) On friendship (Cambridge: Polity Press).

Parker, D. \& Song, M. (2006) Ethnicity, social capital and the internet: British Chinese websites, Ethnicities, 6(2), pp. 178-202.

Portes, A. (1998) 'Social capital: its origins and applications in modern sociology', Annual Review of Sociology, 24, pp. 1-24.

Ryan, L., Sales, R., Tilki, M. \& Siara, B. (2008) Social Networks, Social Support and Social Capital: The Experiences of Recent Polish Migrants in London, Sociology 42(4), pp. 672-90.

Ryan, L., Sales, R., Tilki, M. \& Siara, B. (2009) Family Strategies and Transnational Migration: Recent Polish Migrants in London, Journal of Ethnic and Migration Studies, 35(1), pp. 61-77.

Rodriguez, V. (2001) Tourism as a recruiting post for retirees, Tourism Geographies, 3(1), pp. 52-63.

Rojeck, C. (2005) An outline of the action approach to leisure studies, Leisure Studies, 24, pp. 13-25.

Urry, J. (2007) Mobilities (Cambridge: Polity).

Warnes, A. M. (2009) International retirement migration, in: P. Uhlenberg (Ed) International Handbook of Population Aging, pp. 341-363 (Springer).

Williams, A. M. \& Hall, C. M. (2000) Tourism and migration: New relationships between production and consumption, Tourism Geographies, 2(1), pp. 5-27.

Williams, A. M. \& Hall, C. M. (2002) Tourism, migration, circulation and mobility: the contingencies of time and place, in: C. M. Hall \& A. M. Williams (Eds) Tourism and Migration: New Relationships between Production and Consumption, pp. 1-52 (Dordrecht: Kluwer).

Williams, A. M., King, R., Warnes, A. M. \& Patterson, G. (2000) Tourism and international retirement migration: new forms of an old relationship in Southern Europe, Tourism Geographies, 2(1), pp. 28-49. 
Table 1. Sample characteristics of respondents

4

5

6

7

8

9

10

11

12

13

14

15

16

17

18

19

20

21

22

23

24

25

26

27

28

29

30

31

32

33

34

35

36

37

38

39

40

41

42

43

44

45

46

47

48

49

50

51

52

53

54

55

56

57

58

59

60
$\%$

5.8

49.9

35.3

8.2

Average age: 65

Gender

Male

Female

151

41.4

214

58.6

Household size

Single person

66

18.1

Two persons

240

65.8

Three or more persons

52

14.2

Highest educational level Primary school

Secondary school

University

Other

$\begin{array}{cc}6 & 1.6 \\ 177 & 48.5 \\ 179 & 49 \\ 3 & 0.8\end{array}$

Marital status

Single

5

1.4

Married/with partner

292

80

Widow/er

45

12.3

Divorcee/separated

23

6.3

Former occupation

Professional

Managerial and technical

Skilled

Semi-skilled

Armed forces

Never worked

Other

$\begin{array}{cc}152 & 41.6 \\ 91 & 24.9 \\ 70 & 19.2 \\ 19 & 5.2 \\ 1 & 0.3 \\ 2 & 0.5 \\ 24 & 6.6\end{array}$

Current occupation

Self-employed

Retired

In paid employment part-time

In paid employment full-time

Unemployed

Looking after family or home

Long term sick or disabled

Unpaid voluntary work

Other

$\begin{array}{cc}12 & 3.3 \\ 332 & 92.7 \\ 4 & 1.1 \\ 2 & 0.5 \\ 9 & 2.5 \\ 12 & 3.3 \\ 2 & 0.5 \\ 28 & 7.7 \\ 3 & 0.8\end{array}$

Experience living abroad

$\begin{array}{lll}\text { Yes } & 146 & 40 \\ \text { No } & 219 & 60\end{array}$


Table 2. Mobility patterns (1): Return visits to the UK

\begin{tabular}{lcc}
\hline & Frequency & $\%$ \\
\hline Number of visits to the UK & 37 & \\
None & 101 & 10.1 \\
One & 98 & 27.7 \\
Two & 55 & 26.8 \\
Three & 42 & 15.1 \\
Four & 29 & 11.5 \\
More than four & & 7.9 \\
Reasons for visit UK & & \\
Visit friends & 162 & 44.4 \\
Visit relatives & 286 & 78.4 \\
Leisure & 56 & 15.3 \\
Work/business & 30 & 8.2 \\
To access medical services & 31 & 8.5 \\
Other & 24 & 6.6 \\
Accommodation used in UK ${ }^{1}$ & & \\
Own & 73 & 20.0 \\
Rented & 2 & 0.5 \\
Paid (hotel, etc.) & 47 & 12.9 \\
Friends or relatives & 197 & 54.0 \\
Other & 2 & 0.5 \\
Number of weeks spend in UK & & \\
Average 7.31 & & \\
1-3 & & 36.7 \\
4-6 & 134 & 24.9 \\
7-9 & 91 & 7.4 \\
10-12 & 27 & 5.2 \\
More than 12 & 19 & 12.6 \\
\hline
\end{tabular}

Notes: Percentages are of the total sample, including non-respondents to a question.

${ }^{1}$ Responses based on 332 individuals answering they visited UK previous year at least once.

${ }^{2}$ Question with multiple answers possible (per cent calculated over 365). 
Table 3. Mobility patterns (2): Visits from friends and relatives

\begin{tabular}{|c|c|c|}
\hline & Frequency & $\%$ \\
\hline \multicolumn{3}{|l|}{ Visitors from UK } \\
\hline Yes & 358 & 98.1 \\
\hline No & 6 & 1.6 \\
\hline \multicolumn{3}{|l|}{ People from UK visiting last year ${ }^{2}$} \\
\hline Children and/or grandchildren & 279 & 76.4 \\
\hline Other adult relatives & 183 & 50.1 \\
\hline Friends or acquaintances & 244 & 66.8 \\
\hline \multicolumn{3}{|l|}{ Visits by children ${ }^{12}$} \\
\hline 1 week & 83 & 22.7 \\
\hline 2 weeks & 101 & 27.7 \\
\hline Between 2 and 4 weeks & 70 & 19.2 \\
\hline One month or more & 25 & 6.8 \\
\hline \multicolumn{3}{|l|}{ Visits by other adult relatives ${ }^{12}$} \\
\hline 1 week & 79 & 21.6 \\
\hline 2 weeks & 73 & 20.0 \\
\hline Between 2 and 4 weeks & 24 & 6.6 \\
\hline One month or more & 7 & 1.9 \\
\hline \multicolumn{3}{|l|}{ Visits by friends or acquaintances ${ }^{12}$} \\
\hline 1 week & 122 & 33.4 \\
\hline 2 weeks & 81 & 22.2 \\
\hline Between 2 and 4 weeks & 24 & 6.6 \\
\hline One month or more & 17 & 4.7 \\
\hline \multicolumn{3}{|l|}{ Reasons for not having visits ${ }^{2}$} \\
\hline Family problems & 9 & 2.5 \\
\hline Distance & 16 & 4.4 \\
\hline Insufficient room in my home to lodge them & 18 & 4.9 \\
\hline High cost of getting here & 26 & 7.1 \\
\hline Lost touch with them & 6 & 1.6 \\
\hline Other & 21 & 5.8 \\
\hline
\end{tabular}

Notes: Percentages are of the total sample, including non-respondents to a question.

${ }^{1}$ Responses based on 362 individuals answering they received visits from UK last year.

${ }^{2}$ Question with multiple answers possible (per cent calculated over 365 ). 
Table 4. Transnational social contacts

\begin{tabular}{lcc}
\hline & Frequency & $\%$ \\
\hline Contacts with UK through phone, fax and/or mobile & & \\
Daily & 47 & 12.9 \\
Every week (not every day) & 217 & 59.5 \\
Several times a month (not every week) & 64 & 17.5 \\
Once a month & 16 & 4.4 \\
At least once a year (less than once a month) & 16 & 4.4 \\
Never & 2 & 0.5 \\
Contacts with UK through Internet & 92 & 25.2 \\
Daily & 112 & 30.7 \\
Every week (not every day) & 60 & 16.4 \\
Several times a month (not every week) & 22 & 6.0 \\
Once a month & 13 & 3.6 \\
At least once a year (less than once a month) & 59 & 16.2 \\
Never & & \\
\hline
\end{tabular}

Notes: Percentages are of the total sample, including non-respondents to a question. 
2

Table 5. Social contacts with UK: agreement with following statements (percentages in brackets)

\begin{tabular}{lccccc}
\hline & $\begin{array}{c}\text { Strongly } \\
\text { agree }\end{array}$ & $\begin{array}{c}\text { Agree } \\
\text { somewhat }\end{array}$ & $\begin{array}{c}\text { Neither } \\
\text { agree or } \\
\text { disagree }\end{array}$ & $\begin{array}{c}\text { Disagree } \\
\text { somewhat }\end{array}$ & $\begin{array}{l}\text { Strongly } \\
\text { disagree }\end{array}$ \\
\hline $\begin{array}{l}\text { 'I regularly keep in touch with } \\
\text { friends/relatives in the UK' }\end{array}$ & $242(66.3)$ & $98(26.8)$ & $11(3.0)$ & $7(1.9)$ & $2(0.5)$ \\
$\begin{array}{l}\text { 'Back in the UK I have close friends } \\
\text { who I could always turn to for help' }\end{array}$ & $227(62.2)$ & $71(19.5)$ & $31(8.5)$ & $20(5.5)$ & $12(3.3)$ \\
$\begin{array}{l}\text { 'I keep close personal relations with } \\
\text { friends back in the UK' }\end{array}$ & $147(40.3)$ & $107(29.3)$ & $61(16.7)$ & $29(7.9)$ & $12(3.3)$ \\
\hline Notes: Percentages are of the total sample, including non-respondents to a question. & & &
\end{tabular}

Notes: Percentages are of the total sample, including non-respondents to a question. 
Table 6. Level of satisfaction with their contacts with the UK (percentages in brackets)

\begin{tabular}{|c|c|c|c|c|c|}
\hline & $\begin{array}{c}\text { Very } \\
\text { satisfied }\end{array}$ & $\begin{array}{l}\text { Somewhat } \\
\text { satisfied }\end{array}$ & $\begin{array}{c}\text { Neither } \\
\text { satisfied or } \\
\text { dissatisfied }\end{array}$ & $\begin{array}{l}\text { Somewhat } \\
\text { dissatisfied }\end{array}$ & $\begin{array}{c}\text { Very } \\
\text { dissatisfied }\end{array}$ \\
\hline Frequency of visits to UK & $129(35.3)$ & 109 (29.9) & $100(27.4)$ & $11(3.0)$ & $6(1.6)$ \\
\hline $\begin{array}{l}\text { Frequency of contacts with } \\
\text { friends/relatives in UK }\end{array}$ & $159(43.6)$ & $145(39.7)$ & $46(12.6)$ & $9(2.5)$ & $1(0.3)$ \\
\hline $\begin{array}{l}\text { Frequency of visits from } \\
\text { friends/relatives in UK }\end{array}$ & $112(30.7)$ & $151(41.4)$ & $74(20.3)$ & $20(5.5)$ & $3(0.8)$ \\
\hline
\end{tabular}

Notes: Percentages are of the total sample, including non-respondents to a question. 